\title{
A contribuição dos parques infantis de Mário de Andrade para a construção de uma pedagogia da educação infantil*
}

\author{
Ana Lúcia Goulart de Faria **
}

\begin{abstract}
RESUMO: Os Parques Infantis do Departamento de Cultura da Prefeitura Municipal de São Paulo durante os seus três primeiros anos de funcionamento (1935-1938) na gestão de Mário de Andrade integravam projeto governamental de educação não-escolar para as crianças pequenas de família operária, por meio do qual lhes foi garantido o direito à infância. A pesquisa sobre o nosso folclore realizada pelo poeta-educador "300-350" e a diversidade étnica brasileira consistiam o principal fundamento dessa experiência educacional na qual as crianças reviviam as tradições populares e, através da arte e dos jogos tradicionais infantis, tinham a possibilidade de ser criança, de viver a especificidade dessa fase da vida. A planta arquitetônica e o regimento interno dos parques estão aqui destacados revelando entre outras características elementos para a construção de uma pedagogia da educação infantil.
\end{abstract}

Palavras-chave: Criança pequena, pré-escola, cultura infantil,direito à infância, educação infantil

Chamado a um posto oficial, embora não político me vi de chofre desanuviado dos sonhos em que sempre me embalei. (...) Eu fui o filho da felicidade. Nunca sofri. (...) (Mas) agora tendes à vossa frente um

\footnotetext{
* Extraído de minha tese de doutorado (Faria 1994), este artigo é um texto revisto e ampliado do trabalho apresentado no IV Simpósio Latino-Americano de Atenção à Criança de 0 a 6 anos e no II Simpósio Nacional de Educação Infantil, Brasília, novembro de 1996.

** Docente da Faculdade de Educação da Unicamp. Email: anapedro@correionet.com.br
} 
órfão. Não mais filho da felicidade, a felicidade morreu, mas o apaixonado, o ganancioso compartilhador da precariedade humana. (...) As alegrias, as soluções, os triunfos, não satisfazem mais, porque não se dirigem às exigências do meu ser, que eu domino, nem dele se originam;

antes, nascem da coletividade, a ela se dirigem, a esta coletividade monstruosa, insaciável, imperativa, que eu não domino por ser dela uma parte menoríssima (...) Deixei de ser feliz, mas a inocência nasceu. (Mário de Andrade, Oração de Paraninfo, 1935)

O grande poeta brasileiro Mário de Andrade foi um dos idealizadores e diretor do Departamento de Cultura (DC) da prefeitura do município de São Paulo na gestão do prefeito Fábio Prado, quando criou, dentre tantos programas para o operariado, o Parque Infantil (PI) para seus filhos e filhas de 3 a 12 anos. Destacarei aqui o trabalho realizado nos PIs apenas com as crianças pré-escolares de 3 a 6 anos, ${ }^{1}$ pretendendo mostrar a contribuição do referido poeta para as atuais reflexões voltadas à elaboração de propostas de programação educativa que permitam a todas as pessoas de pouca idade tornarem-se crianças e permanecerem como tal durante essa fase da vida.

Criticando as teorias que priorizam o crescimento dos pequenos transformando-os precocemente em alunos, futuros adultos, entendo que o espaço coletivo (com adultos e crianças) como ambiente de educação e cuidado das crianças de 0 a 6 anos tem por objetivo garantir seu direito à infância: o direito a brincar, a não trabalhar, a expressarem-se das mais variadas formas e intensidades, promovendo o exercício de todas as dimensões humanas (lúdica, artística, do imaginário etc.) e possibilitando a construção do conhecimento espontâneo, do imprevisto, da cultura infantil e seu intercâmbio com os adultos e suas culturas. Em vez de refletir sobre o desaparecimento da infância, como vêm fazendo alguns estudiosos estrangeiros, parto da criança como produtora e consumidora de cultura tendo no espaço coletivo das creches e pré-escolas o local privilegiado para permanecer criança; será portanto aí que uma nova descoberta da infância pelo adulto ocorrerá, podendo dar continuidade ao trabalho iniciado nos Pls.

Os parques infantis criados por Mário de Andrade em 1935 podem ser considerados como a origem da rede de educação infantil paulistana (Faria 1995) - a primeira experiência brasileira pública municipal de educação (embora não-escolar) para crianças de famílias operárias que tiveram a oportunidade de brincar, de ser educadas e 
cuidadas, de conviver com a natureza, de movimentarem-se em grandes espaços ${ }^{2}$ (e não em salas de aula, como se pode verificar na planta arquitetônica em anexo). Lá produziam cultura e conviviam com a diversidade da cultura nacional, quando o cuidado e a educação não estavam antagonizados, e a educação, a assistência e a cultura estavam macunaimicamente integradas, no tríplice objetivo parqueano: educar, assistir e recrear.

Hoje em dia, apesar de a polêmica educação versus assistência tender a uma abordagem sem antagonismo na educação infantil, ainda a tradição da pesquisa na área que identificava educação com escola tem prejudicado a construção de programas educativo-socioculturais para as crianças de 0 a 6 anos antes do ingresso na escola de $1^{\circ}$ grau. Analisando o documento que justifica a criação das Escolas Municipais de Educação Infantial (Emeis) na mesma prefeitura de São Paulo em 1974, pode-se notar a separação entre cuidado e educação que estavam unidos no $\mathrm{PI},{ }^{3}$ assim como se nota a eliminação por completo dos seus objetivos iniciais relacionados ao lúdico, aos jogos tradicionais infantis, ao artístico, enfim, abandonando uma concepção de criança competente e capaz, sujeito de direitos, criadora e consumidora da cultura e não apenas um aluno, geralmente entendido como consumidor da cultura produzida por outros, sendo precocemente escolarizado.

Seria interessante verificar quais as outras experiências brasileiras em educação infantil que estavam (ou estão) fundamentadas na cultura, que com certeza, como os PIs, terão muito a contribuir para superar antagonismos ainda hoje existentes para a elaboração de uma programação pedagógica não-escolar para as crianças pequenas em instituições coletivas de cuidado e educação, as creches e pré-escolas. ${ }^{4}$ Afinal, a idéia de educar fora de casa e fora da escola já é bastante antiga e, de alguma forma, já estava contida no Manifesto dos Pioneiros de 32 que, vendo a criança pequena de uma forma mais global, não separava educação, cultura e saúde. Creio que essa é uma das razões pelas quais a Escola Nova tem sido até hoje sistematicamente criticada, principalmente pelo pesquisador que, priorizando as questões de ensino de uma forma unilateral, não vê a relação dialética existente entre aprender e permanecer criança, vendo a criança apenas do ponto de vista biológico como um vir-a-ser, em vez de vê-la também na sua dimensão cultural, isto é, também com sua especificidade infantil, enquanto uma fase da vida a ser vivida no seu tempo: tornando-se criança, sem precisar transformar-se em adulto rapidamente, encurtando sua infância. 
Os fundamentos do PI correspondiam a idéias existentes também fora do Brasil nos anos 20 e 30 , algumas delas ainda pouco estudadas entre nós, como por exemplo as idéias sobre arte e imaginário infantil do soviético Vygotsky e sobre teatro proletário (entre outros tantos textos sobre criança e infância) de Walter Benjamin, ${ }^{5}$ semelhantes a algumas idéias de Mário de Andrade e dos modernistas brasileiros. Todos contemporâneos de um período no qual em várias partes do mundo estavam adotando o jogo, as áreas abertas e o nacionalismo, porém, com objetivos distintos (e até antagônicos, como foi o caso do nazismo e do fascismo) para a educação das crianças.

O idealismo de Mário de Andrade, sua atenção e seu respeito para com as crianças, e suas características de grande educador (além de ter sido professor de música e de piano no Conservatório Dramático e Musical de São Paulo e professor de filosofia e história da arte na Universidade do Distrito Federal no Rio de Janeiro) fazem com que ele conceba um PI diferente das experiências com jogo, espaço aberto e nacionalismo existentes para disciplinar o operariado: enquanto as crianças estavam no parque, não estavam trabalhando, estavam conhecendo várias manifestações da cultura brasileira, ${ }^{6}$ estavam expressando-se das mais variadas maneiras, convivendo com a natureza e com pessoas de idade e origem étnica e cultural diversificadas. Além de não ter separado cuidado-educação-cultura, o lúdico foi entendido como elemento integrante da cultura dos povos, idéia já formulada pelo professor alemão Huizinga, que em 1933 polemiza sobre o jogo como elemento da cultura no seu discurso anual como reitor da Universidade de Leyden e lança seu livro Homo Ludens em 1938, afirmando no prefácio:

Seria mais ou menos óbvio, mas também um pouco fácil, considerar "jogo" toda e qualquer atividade humana (...) Não vejo, todavia, razão alguma para abandonar a noção de jogo como um fator distinto e fundamental, presente em tudo o que acontece no mundo. Já há muitos anos que vem crescendo em mim a convicção de que é o jogo e pelo jogo que a civilização surge e se desenvolve. É possível encontrar indícios dessa opinião em minhas obras desde 1903 (...) minha intenção não era definir o lugar do jogo entre as outras manifestações culturais, e sim determinar até que ponto a própria cultura possui um caráter lúdico. O objetivo deste estudo mais desenvolvido é procurar integrar o conceito de jogo no de cultura. (Huizinga 1971) 
A educação estética, a arte e a arte infantil, o folclore como manifestação das raízes múltiplas do brasileiro caracterizam o PI e o DC como um projeto governamental coerentemente integrado ao projeto maior de urbanização da Paulicéia.

Para entender melhor o PI como proposta educacional ainda válida para os nossos dias, será importante observar que as idéias de Mário de Andrade a respeito da construção de uma identidade nacional englobavam todas as faixas etárias e todas as camadas sociais. Através das manifestações populares, folclóricas, artísticas e estéticas, a infância e o operariado estavam presentes consumindo e produzindo cultura, abrasileirando, portanto, o país. Seus fundamentos não eram os da educação escolar da época, que o poeta criticava. Todavia, as ambigüidades características dos anos 30 no Brasil são visíveis também nessa área da educação infantil. O jogo, como atividade lúdica, ociosa, muitas vezes foi negligenciado por aqueles que, embora valorizando a recreação na educação pré-primária e nos jardins-de-infância, destacavam sua finalidade de facilitar a tarefa da escola primária. Neste caso, o fator lúdico perde sua importância. Exemplo disso é a fala ambígua de Comenius recomendando como fundamental que "as crianças devem estar ocupadas em trabalhos, sejam sérios, sejam recreativos, para que não se habituem ao ócio" (Comenius, apud Marinho 1971, p. 142).

Essa forma de instrumentalizar o jogo e as brincadeiras, retirando o aspecto gratuito, do prazer pelo prazer, parece não estar presente nas metas de Mário de Andrade. Utilizando os rituais, as músicas, ${ }^{7}$ as danças e as apresentações folclóricas como atividade das crianças no $\mathrm{PI}^{8}{ }^{8}$ o lúdico estava presente juntamente com o artístico. No entanto, todas essas diferentes formas de conceber o jogo coexistiam. Nicanor Miranda (chefe da Divisão de Ensino e Recreio, onde estavam alocados os PIs), por exemplo, pouco destacou o folclore e o artístico quando escreveu tantos textos sobre jogos e brincadeiras. Na verdade, como naquela época já dizia Caillois (1982), a atividade lúdica é um continuum com duas extremidades: uma, ocupada por jogos que manifestam criatividade, fantasia, espontaneidade; e outra, com os jogos convencionais, subordinados a regras. Na vida social, sempre existem regras, que variam de sociedade para sociedade, portanto, o jogo infantil, naquele continuum, pode tanto ensinar a obediência a elas, como também pode ensinar a sua arbitrariedade. Através das manifestações folclóricas, as crianças do PI estavam conhecendo vários tipos de "regras", de sociedades diferentes, momentos históricos distintos, poden- 
do, com isso, ter variadas experiências lúdicas entre as referidas extremidades: da mera obediência disciplinadora, à pura fantasia ociosa.

A busca de uma identidade nacional que não exclui nem as crianças nem os operários, e a crítica à educação escolar que aponta para a necessidade de a escola ser complementada com outras formas de educação (convivendo com práticas disciplinadoras próprias de instituições dessa natureza) podem fazer do PI um instigante objeto de estudo para as áreas da pedagogia e da educação e políticas sociais. A paixão com que seus idealizadores, administradores, ex-educadores e ex-usuários referem-se a ele nos convida a não aceitar a interrupção desse processo em relação à educação infantil brasileira. Eis dois depoimentos de exfreqüentadores do PI da Lapa: ${ }^{9}$

Nós, crianças, brincávamos na rua. Agora, com o parque, meus pais podiam trabalhar mais tranqüilos, ele na SP Railway e ela na fábrica de tecidos. O parque para nós foi a liberdade. Aqui podíamos nos divertir sem vizinhos brigando: "Não faça isso, não pule o muro, não suba na cerca!"

Mas é que no parque eu tinha tudo o que precisava: as professoras que tomavam conta, aulas de música, crochê, bordado; era tanta coisa boa que eu ficava por aqui mesmo, não voltava para casa. (Escola Municipal 1985, pp. 6-29)

O próprio Mário de Andrade criticava a pedagogia contemporânea de sua época e a ineficácia da "cultura minúscula dos nossos grupos escolares sem nenhuma continuidade nesses trabalhos manuais..." (Mário de Andrade, 13/4/1941 apud MAC-IEB 1988), mostrando a necessidade de não excluir os institutos de cultura dos programas de alfabetização. Ele disse em carta para Paulo Duarte:

Cumpre organizar os serviços, forçar a vitalidade dos museus e a criação de institutos culturais que ajam pelos processos educativos extrapedagógicos que cada vez mais estão se tornando os mais capazes de ensinar. O que há talvez de mais admirável na pedagogia contemporânea é o seu caráter, por assim dizer, antipedagógico; justamente o engurgitamento da massa mais oculta dos estudantes, nivelando-a à dantes melancólica elite professoral, pelo respeito às suas qualidades e tendências próprias, de massa e de sombra. 
Serão assim os museus, os institutos culturais que desejaria espaIhados com mais freqüência entre nós. Sim, temos enorme necessidade de escolas primárias e de alfabetização. Mas a organização intelectual de um povo não se processa cronologicamente, primeiro isso e depois aquilo. Tanto mais em povos criança e contemporâneos como o nosso, com avião, parques infantis, rádio, bibliotecas públicas, jornal, e impossibilitados por isso de qualquer Idade Média.

Não entreparemos portanto no sofisma sentimental do ensino primário. Ele é imprescindível, mas são imprescindíveis igualmente os institutos culturais em que a pesquisa vá de mãos dadas com a vulgarização, com a popularização da inteligência. (Setembro de 1937, apud Duarte 1971, p.153, grifo meu)

O ambíguo Nicanor Miranda, em 1938, no discurso de inauguração do quarto PI, o de Santo Amaro, foi bastante feliz ao enfatizar o caráter complementar do $\mathrm{PI}$ em relação à escola, criticando-a com as idéias do educador argentino Ernesto Nelson:

A escola é o lugar onde a criança tem que ficar sentada, bem quietinha, quatro horas por dia e nove meses por ano, absorvendo abstrações e sem a prática da experimentação. Tudo se passa como se o interesse da criança gravitasse em torno de livros, silêncio, passividade, inatividade. A escola é ainda individualista, na época em que vivemos, não se propondo a ensinar cooperação, iniciativa, autodireção ou a arte de fazer amigos e dirigir os outros. Violando as leis do crescimento físico e psíquico, prepara homens sem iniciativa, sem vontade, sem idéias. Forma pulmões e corações débeis, braços e pernas macilentos e debilitados, gerando na criança uma anemia e uma constituição acanhada e incompleta (...) Ao invés de respeitar o corpo e deixar a mente cuidar de si mesma, respeitamos a mente e descuidamos do corpo. Ambas as atitudes são erradas, mas não podemos deixar de reconhecer esta verdade tão simples: o físico serve de base ao mental e este último não deve ser desenvolvido em prejuízo do primeiro. A escola não é, pois, o sistema ideal de cultura infantil. Um outro sistema precisa, não diremos substituí-la, mas completá-la. Um sistema que tome a criança como ela é, e a nossa complexa civilização como ela é, harmonizando os dois fatos de uma maneira científica e ao mesmo tempo humana. Este é o parque infantil. ${ }^{10}$ 
Quase antagônico, mas propondo-se a ser complementar à escola, o PI ousou. Em relação às crianças em idade pré-escolar, não foi encontrada nenhuma referência voltada a sua preparação para a escola, pré-alfabetização, currículo com disciplinas etc. Pelo contrário, como complemento escolar, o PI oferecia para as crianças alunas da "escola primária" (que a freqüentavam alternadamente ao parque), e para as outras pequenas freqüentadoras de 3 a 6 anos, a oportunidade de se expressarem artisticamente, brincarem e jogarem, enfim, de continuarem crianças, complementando o aluno que a escola pretende formar, visto muitas vezes como um ser incompleto que precisa ser completado com os conhecimentos científicos de que o adulto e a sociedade dispõem, não raramente, deixando de lado outros conhecimentos como aqueles produzidos pelas próprias crianças, assim como outras manifestações de produção de saberes. Mais uma vez citarei a revista comemorativa dos 50 anos da pré-escola paulistana, elencando as atividades desenvolvidas nos parques, mencionadas nos depoimentos de seus ex-usuários e ex-professores:

atividades de campo ("tanto que quase não existiam salas"); "o repouso era o que eles mais gostavam"; banho; trabalhos manuais; tecelagem; quebra-cabeças; damas; "eu dividia em grupos, as pequenininhas com uma menina de 11 ou 12 anos que contava história, outro grupo jogava bola enquanto eu dava aula de educação física ${ }^{11}$ para os grandes"; lanche, duas vezes ao dia; reuniões semestrais (orientação quanto à programação musical); ; "anotações nos relatórios que eram passadas para o maestro que os citava nominalmente nas reuniões"; comemorações cívicas; festas com a comunidade uma vez por mês, "cada mês a festa era em um parque e os outros iam participar"; palestras para as mães; relatórios diários de atividades; "no fim do mês era registrado e feito um balanço" - sem o relatório não se recebia (o salário); planos mensais; aulas de música; crochê; bordado; ginástica: barra, salto em altura; "a Dona Cida nos examinava, pesava, media o tórax e anotava tudo em fichas", cricket; tanque de areia; balanço; piscina; tricô; gangorra; peças de teatro, "depois a gente ia mostrar as peças nos outros parquinhos"; desenhos; biblioteca. (Escola Municipal 1985, pp. 19-29)

Não só o PI, mas o DC como um todo era um projeto de educação extra-escolar que garantia o direito ao espaço público para o ope- 
rariado, fazendo parte do projeto municipal de urbanização da cidade, atendendo à Constituição da época que exigia a utilização de $10 \%$ do orçamento da prefeitura com os sistemas educativos. Para não reproduzir o modelo escolar, a ênfase do PI estava no aspecto lúdico, nas brincadeiras, nos jogos tradicionais infantis; e os objetivos oficiais dessas escolas populares de saúde e alegria eram educação moral, higiênica e estética (Ato 767, de 1935, art. 50 i. DC,1936). Por isso mesmo, uma das funções da instrutora era observar a criança e estudá-la nos seus aspectos higiênico, psicológico e social (idem, art. $5^{\circ}$ f). Muitos desses estudos foram publicados na Revista do Arquivo Municipal da época. ${ }^{13}$

Além da pesquisa, da observação e da divulgação do trabalho realizado, como podemos verificar no "Regimento Interno" (que com certeza merece outras análises, principalmente do ponto de vista dos seus aspectos mais rígidos, embora nunca escolarizantes...), no PI as instrutoras também deveriam brincar com as crianças, ensiná-las a brincar e preservar as brincadeiras tradicionais $\left(1^{\circ} \mathrm{h}, \mathrm{i}, \mathrm{j}\right)$ e não lhes perturbar ou ameaçar sua liberdade e espontaneidade $\left(1^{\circ} \mathrm{f}\right)$. $\mathrm{O}$ respeito à produção das crianças estava assegurado ( $\left.2^{\circ} \mathrm{j}, \mathrm{k}\right)$ já que seus desenhos deveriam ser enviados para o DC com os respectivos nome e idade. A instrutora tinha muitas responsabilidades em relação à organização e à manutenção do espaço físico ( $4^{\circ}$ item), seu "instrumento de trabalho". Era proibido o uso de varinhas e bastões... ( $\left.2^{\circ} n\right)$. Para isso, os adultos-educadores precisavam ser educados. Entre tantos aprendizados, elas não deveriam tirar lições de moral das manifestações folclóricas. Eis um trecho de um documento do DC de 1939, esclarecendo-as:

Um problema delicadíssimo de aproveitamento da coisa folclórica para material das entidades educativas é o da moralização dos textos (...) Até que ponto a moralização dos textos não os tornará rançosos, estupidamente rígidos, repulsivos ao recreio infantil (...) O costume freqüente em meios didáticos, de transportar para instituições escolares o próprio cancioneiro infantil, "moralizandoo", nos parece obsoleto e execrável. A criança aprende a sua roda em casa ou na rua e vai encontrá-la na escola com modificações de palavras e deformações de sentido. Fica-lhes assim a atenção chamada justo para as palavras e as idéias possivelmente imoralizadoras; cria-se-Ihes um fundo de malícia e ao mesmo tempo de hipocrisia, porventura mais prejudicial que as próprias canções. Tanto mais que as canções "moralizadas" são impostas sem qualquer explicação suplementar. 
Podemos dizer que esse espaço coletivo de convívio entre crianças (de várias idades, meninos e meninas, de origens culturais diversas), entre adultos (educadoras sanitárias, instrutoras, médicos, vigilantes, zeladores, mães) e entre adultos e crianças pode ter dado origem a uma pedagogia das diferenças, uma pedagogia das relações, à qual pretendemos dar continuidade e na qual a criança é a protagonista.

Dessa forma, a preocupação com a educação no PI ultrapassa a da "escola primária" da época, já que esse não desconsiderou as formas não-científicas de produção do conhecimento, como a arte, o folclore e o conhecimento espontâneo da criança, construído através dos jogos e das trocas entre as crianças e entre elas e os adultos. ${ }^{14}$

A constituição da identidade brasileira e o ingresso na modernidade através do nacional, passando pela cultura popular e pelo resgate das tradições, têm na pesquisa folclórica realizada por Mário de Andrade grande parte de seus fundamentos, sempre evidenciando o que hoje chamamos de circularidade cultural. $O$ folclore pode ser encarado e utilizado de várias maneiras. Mário de Andrade critica aqui uma delas:

Ainda há outra praga, não sei se universal, mas que se especializou entre nós em prejudicar o Folclore. É que além da indiferença dos governos e dos milionários, o Folclore científico sofre no Brasil a concorrência impudica do amadorismo, escandalosamente protegido pelas casas editoras e o aplauso do público (...) O Folclore no Brasil ainda não é verdadeiramente concebido como um processo de conhecimento. Na maioria das suas manifestações, é antes uma forma burguesa de prazer (leituras agradáveis, audições de passatempo) que consiste em aproveitar exclusivamente as "artes" folclóricas, no que elas podem apresentar de bonito para as classes superiores. Na verdade este "folclore" que conta em livros e revistas ou canta no rádio e no disco, as anedotas, os costumes curiosos, as superstições pueris, as músicas e os poemas tradicionais do povo, mais se assemelham a um processo de superiorização social das classes burguesas. Ainda não é a procura do conhecimento, a utilidade de uma interpretação legítima e um anseio de simpatia humana. (Andrade 1949, pp. 285-286, grifos meus).

Assim, a criança para Mário de Andrade é portadora da cultura de sua classe e o PI é um local privilegiado para conhecê-la. Portanto, baseado na produção cultural, o PI foi criado como uma alternativa às pré- 
escolas existentes, assim como uma alternativa para os espaços filantrópicos existentes na época para as crianças pobres. Dessa forma, Mário de Andrade não só fez a coisa pública ser de fato pública, como qualificou o serviço público, promovendo melhores condições de vida para uma clientela pouco atendida: os filhos dos operários, contemplados, portanto, já sob a responsabilidade do município, com o direito à infância, isto é, com o direito ao não-trabalho, com o direito de brincar e de criar a cultura infantil, permanecendo crianças pelo menos enquanto estivessem no parque.

Embora os PIs fossem destinados às crianças maiores de 3 anos, mesmo sendo para os filhos dos operários, seu enfoque era na própria criança, e não apenas no direito trabalhista de sua mãe. No entanto, a família estava sempre presente, não apenas nas festas, mas como portadora de uma cultura, integrando a diversidade cultural do país. Dessa maneira, os PIs já eram um espaço educativo complementar (e não substituto) à família e também à escola. Mesmo assim, às vezes o PI é apontado como um projeto apenas para a assistência das crianças pobres, ignorando o caráter educacional embutido também aí (Kulhmann Júnior 1991). Será que é por essa razão que uma experiência não-escolar inovadora e provida de intencionalidade educativa não teve continuidade? Será que foi justamente por ser inovadora que se isolou e daí a não-continuidade? (Lembremos que os PIs também foram analisados como disciplinadores da classe operária; no entanto, Mário de Andrade demitiu-se do DC pressionado por Getúlio Vargas.) Será que é por isso que tem sido ainda ignorado por muitos educadores o caráter avançado do projeto de Mário de Andrade que colocava a criança em primeiro lugar, seja como oportunidade de os adultos conhecerem-na melhor, seja valorizando a própria infância através das tradições culturais brasileiras e possibilitando o imprevisto e o novo que nascem aí?

Ao lado do folclore, jogos e brincadeiras, as diferentes manifestações artísticas compunham as atividades principais do $\mathrm{PI}$, fazendo com que as crianças participassem do projeto de construção da cultura nacional. Mário de Andrade acreditava que a criança não só aprende e consome a cultura do seu tempo, como também produz cultura, seja a cultura infantil de sua classe, seja reconstruindo a cultura à qual tem acesso.

Mário de Andrade estudou a criança principalmente do ponto de vista das manifestações artísticas. Já em 1929 encaminhou ao Congresso de Arte Popular em Praga seu estudo sobre "A influência portuguesa nas rodas infantis"; em 1931 publicou no Diário Nacional, o artigo "Pintu- 
ra Infantil", referindo-se à "liberdade de expressão" como uma das qualidades da arte da criança (nos anos 40 substitui por "expressão pessoal").

No final dos anos 20, Mário já havia escrito sobre criança e arte: "O pai do gênio" (Diário Nacional) e "Da criança-prodígio I, II, III" (coluna Taxi). Nesses artigos, Mário de Andrade contribui sobremaneira para a pedagogia e a educação infantil, descobrindo novas características da criança pequena, colaborando dessa forma para ampliar a formação do educador a respeito dessa fase da vida. A sua sensibilidade em relação às crianças era algo notável: seu texto "Sonoras crianças" é um estudo de algumas composições musicais de Villa Lobos, Schumann e outros, em que esses puseram em sons sua compreensão do mundo infantil. Mário "decifra" essa linguagem como músico, porém, do ponto de vista da criança. Vejamos um pequeno trecho:

A mim, que adoro as crianças e me aproximo sempre intimidado e comovido do seu cantinho, a atitude do mestre frances (Debussy) me desagrada muito (...) pois das peças do "Children's corner", a que demonstra um laivo mais sensível de ternura (embora de elefântica ternura) é o acalante dedicado ao elefantinho Jimbo recém-nascido... Quanto a Schumann (...) ele observa amorosamente a gurizada em seus brinquedos e em certas reações fisiológicas do sono, do tombo, etc. Mas ainda se contenta mais em descrever coisas observadas, que em interpretar a criança, penetrando-Ihe no íntimo (...) a criança não é apenas um ser descuidado, vivendo da alegria dos brinquedos e das pequenas reações diante de dores sem importância humana; é também um drama, a criança tem seu drama, tem seu mistério impenetrável.(...) Mussorgsky não apenas reconhece a existência de um drama infantil que ele não consegue penetrar, como Schumann. Pelo contrário, é este drama, é mesmo o trágico infantil que ele se propõe a interpretar (...) Dir-seá que ele interpreta crianças russas... Mas a verdade é que a alma de pouca idade ainda está racialmente muito pouco diferençada; é o período de maior universalidade do ser humano, e isto se pode perfeitamente provar pela existência de bonecas e de acalantos em todas as raças, classes e civilizações, desde o inglezinho mais europeamente civilizado até o vedazinho mais primário (...) O grande compositor brasileiro foi realmente o único dos compositores que até agora nos deu a história da criança. E se lhe descreveu sorridentemente as felicidades e lhe interpretou gravemente o trágico psicológico, na 
série incomparável das "Cirandas", fundiu inventivamente a graça e o drama, pelas formas bipartidas em que a primeira parte intensamente dramática se continua por uma segunda, florida pelas nossas cantigas-de-roda, que são das mais belas do mundo. (Mário de Andrade 1963, pp. 303-308)

Comparando a arte infantil com a arte primitiva, discordava de Luquet que relacionava criança e nascimento da arte. E mesmo sofrendo influência das idéias evolucionistas da antropologia daquela época, de que a ontogênese reproduz a filogênese, Mário de Andrade diz que a arte da criança não repete (sempre) a história da humanidade ${ }^{15}$ e afirma no seu texto "Realismo Intelectual":

A criança não só inverte a ordem da criação como inverte também a ordem dos estilos que o prehistorico nos apresenta, pelo que dele sabemos até agora. Trata-se exatamente pois de um idealismo. Quando o Futurismo italiano, desejoso de ser mais realista que o real, pretendeu representar o objeto não só no que era visto, mas nas diversas maneiras com que podia ser visto, agora sim, ele caiu num realismo intelectual que partia exclusivamente das possibilidades sensoriais da visão (...) Ao passo que no desenho da criança não há escolha voluntária de tal ou qual aspecto visual possível do objeto, mas uma imposição fatal, um imperativo categórico da noção definidora, do conceito, de idéia universal que a mentalidade infantil se faz do objeto (...)

O instinto de apropriação, o egoísmo imperialista da criança, Ihe impõe a linha abstraída que determina os limites de uma qualquer propriedade (...) agora sim estamos exatamente dentro de uma síntese, isto é, dentro de um fenômeno exclusivamente intelectual, dependente da realidade apenas porque a completa e delimita um ideal. Pouco importa, está claro, que esta síntese infantil se nos apresenta como grosseira e incompleta.

Quando a criança passa desse idealismo definidor para o realismo visual, muito embora esta passagem se dê gradativamente, os dois processos aliás se manifestando concomitantemente desde o início, jamais havendo manifestações do chamado "realismo intelectual" integrais (...) quando a criança passa de uma fase para outra, na verdade não se deu passagem alguma. (Andrade 1966, grifos meus) 
Desde os anos 20, Mário de Andrade já colecionava desenhos de crianças que, juntamente com os desenhos realizados nos Pls e encaminhados para o DC (com nome e idade das crianças autoras) e os do concurso promovido pela Biblioteca Infantil, serviram-Ihe de base para o desenvolvimento de interessante reflexão sobre arte-educação na infância, futuramente matéria de suas aulas no Instituto de Artes da Universidade do Distrito Federal, para os alunos do curso de filosofia e história da arte. (Mário fez uma bela coleção daqueles desenhos, expostos em 1988 nas comemorações dos 25 anos do Instituto de Estudos Brasileiros da USP e do Museu de Arte Contemporânea.) A grande reverência de Mário para com a infância pode ser encontrada também nas anotações para sua 6⿳a aula "o primitivo-a criança". ${ }^{16}$

O concurso de desenho infantil promovido pela Biblioteca Infantil do DC era de livre participação, com material de ótima qualidade e havia a recomendação de que as educadoras não interferissem. Atrás de cada desenho estavam escritos o nome e a idade da criança e a nacionalidade do pai e da mãe. Mário de Andrade, que já havia escrito alguns artigos sobre a arte infantil, passou a escrever vários outros sobre o mesmo assunto.

Discordando ainda de Luquet, Mário de Andrade pode ser visto também como um pioneiro das idéias relativas ao desenho como antecipação da escrita, como forma de grafismo, como uma das linguagens. No mesmo texto já apresentado, ele continua:

pelo que sabemos da criança até agora, que até um certo ponto abandonando os fatores estimulantes, a criança realiza por sua conta e risco, pela sua própria experiência, um, não 0 , mas um nascimento do poder humano a representação figurativística. Mas desde que passa desta fase, que é de caráter lingüístico, hieroglííco, e não pesquisa de sensações, ela abandona totalmente a evolução gradativa do grafismo idealista, da criação de uma escrita, que vinha fazendo. Não há mais evolução: se dá mudança completa do rumo. E esta mudança coincide com um desenvolvimento mental em que a criança já se tornou sensível aos fatores da hereditariedade, dos contágios e da alfabetização. (Andrade 1966)

Em seu artigo "Do desenho", Mário diz que o desenho, assim como a dança, faz parte das artes intermediárias entre as artes do espaço e as artes do tempo. Segundo ele: "Se a dança é uma arte intermediária que 
se realiza por meio do tempo, sendo materialmente uma arte em movimento, o desenho é uma arte intermediária que se realiza por meio do espaço, pois sua matéria é imóvel" (Andrade 1975, pp.71-77).

A pintura é diferente, pois busca elementos de eternidade, e quando se utiliza do traço, está invadindo o domínio do desenho que é um jeito de definir transitoriamente: "Ele cria, por meio de traços convencionais, os finitos de uma visão, de um momento, de um gesto. Em vez de buscar as essências misteriosas e eternas, o desenho é uma espécie de definição, da mesma forma que a palavra 'monte' substitui a coisa 'monte' para nossa compreensão intelectual” (idem).

Para Mário de Andrade, assim como o provérbio, o desenho é ao mesmo tempo uma transitoriedade e uma sabedoria. Não representa nenhuma eternidade, mas a verificação de um momento. Portanto, podemos afirmar que, para ele, o desenho é uma linguagem: "Desenhos são para a gente folhear, são para serem lidos que nem poesias, são haicais, são rubaes, são quadrinhas e sonetos" (idem).

Eis mais alguns dos comentários feitos por Mário de Andrade quando do seu estudo sobre os desenhos infantis:

- Foi encontrada pouca influência do cinema e dos livros nos desenhos dos Parques Infantis (crianças de 3 a 14 anos) e grandíssima influência nos desenhos das crianças ( 6 a 16 anos) da Biblioteca (geralmente freqüentada por crianças burguesas).

- No P.I. do Ipiranga, houve igualdade de concorrência entre os sexos. Nas primeiras idades (3,4,5 anos) nota-se nas mulheres mais capacidade para representar imagens experimentadas.

- No P.I. da Lapa quase só concorreram meninas. Os meninos da zona despresam o desenho (...) De 11 anos em diante houve bom número de meninos concorrentes.

- Somente nos desenhos realizados na Biblioteca "se lembraram de virar o papel que era solto" (nos P.I. o papel estava deitado, com o lado maior para baixo). (Andrade 1966)

Mário tanto ensinou como aprendeu com as crianças; gostava de contar histórias para elas e ouvir as que tinham para contar. Além do concurso do desenho infantil, do concurso do livro infantil e de tantas outras atividades desenvolvidas pelo PI em benefício da criança, por ocasião do 
I Congresso de Língua Nacional Cantada, que tinha o objetivo de estabelecer as normas da pronúncia do canto, realizado no Teatro Municipal, em 1937, por iniciativa do DC, os PIs participaram de duas maneiras: na primeira, apresentando seu estudo sobre a formação e a articulação da palavra (Miranda e Reis, "Vícios e defeitos na fala das crianças dos parques infantis de São Paulo"), e na segunda, as crianças representaram o bailado tradicional popular do nordeste "A Nau Catarineta" ou "Marujada" (de origem portuguesa, pesquisada e adaptada por Mário de Andrade).

É bom esclarecer que Mário de Andrade não teorizou sobre os jogos e brincadeiras no PI (aliás, poesia não é lugar de teoria...). Embora tenha tido muitos insights em relação às manifestações infantis e sua educação, afirmou certa vez: "Mas que ninguém pense de mim que tive a menor intenção de fazer verdade por todos estes comentários. Sem pesquisas mais numerosas e aprofundadas dirigidas com maior método, tudo são imaginações improváveis que sempre poderão ficar a meio caminho entre a ficção e a verdade" (16/4/41, apud MAC-IEB 1988).

Será nos seus escritos sobre os objetivos culturais do DC e sobre suas utopias em relação à identidade nacional e à brasilidade, e nos seus escritos sobre arte e arte infantil, que poderemos ver, ao lado de seu amor pelas crianças (e entre seus vários personagens-criança ao longo de sua obra ${ }^{17}$ ), não só o que estou chamando de direito à infância, como também o PI como um espaço de prazer, um lugar de vida, de criação da cultura infantil onde as crianças, convivendo entre elas e com os adultos, tornavam-se e permaneciam crianças.

A preocupação com as questões sociais, característica da gestão de Fábio Prado e do momento político que se vivia no Brasil daquela época, apresenta por parte do DC e do PI elementos novos, como o folclore e a questão estética, que permitirão englobar a infância e a classe operária, do ponto de vista da atenção e do respeito, e não apenas do controle, já que não se tratava exclusivamente de uma proposta de lazer na sociedade do trabalho, mas de uma proposta que resgatava as origens do povo americano que, de acordo com Mário de Andrade, é preguiçoso, sonhador... macunaímico. Se, por um lado, podemos ver as iniciativas do DC disciplinando o tempo livre das crianças e do operariado, podemos ver também, por outro lado, concomitantemente, inspirada no poeta, a garantia de um espaço público para essas pessoas não fazerem "nada de útil", produzirem sua cultura (geralmente não considerada "útil”...), recuperando o aspecto gratuito da dimensão lúdica, tão temido e rejeitado pela sociedade do 
trabalho; além de terem acesso a uma cultura outra, desconhecida por eles e inclusive, na maior parte das vezes, impedida de ser-lhes conhecida.

Uma forma de conhecer a vida material e a organização social embutidas nas mais diferentes tradições populares, dando voz ao silenciado, caracterizou as pesquisas de Mário de Andrade que, preocupado com a identidade nacional, pretendia fazer a cultura popular conhecida da elite, que deveria estar consciente do papel do folclore na formação da identidade brasileira.

É muito importante observar essa forma de Mário de Andrade reconhecer e aceitar as diferenças culturais. O diferente é um outro, que faz parte do conjunto da população que constrói a identidade nacional, concepção essa bastante distinta de outros folcloristas. ${ }^{18}$

O professor italiano Ettore Finazzi-Agrò, estudioso de Mário de Andrade e da literatura brasileira, afirma:

...para Mário de Andrade esta mesma alteridade acaba por ser a bordeline para além da qual é possível "afigurar" as infinitas eventualidades de identificação do povo brasileiro. "Pensar o outro" torna-se, afinal, no Mundo Outro, o único modo de pensar a identidade: renunciando a priori a toda a coerência ou, melhor ainda, buscando na incoerência a única possível coerência, na metamorfose e na precariedade a única verdadeira persistência. A persistência do neutro dentro e através do multíplice. (1988, p. 448)

É óbvio que, para um organizador de política cultural com aspirações a transformar o Brasil num país moderno, a cultura e a educação eram elementos intrínsecos, próprios das preocupações de uma esfera pública redimensionada, ampliada com o tempo do não-trabalho: seja o do lazer operário, seja o da educação dos que não devem trabalhar: as crianças. ${ }^{19}$ No entanto, quando fala em transformar o país, Mário de Andrade fala em cultura, na cultura produzida e consumida pela elite $e$ pelo povo, destacando que esse direito do povo é um dever dos governos (Duarte 1971, p. 153).

Como um antiacadêmico pesquisador (assim se definiu em carta para Cascudo, 26/9/1924), Mário de Andrade trouxe aos educadores 
uma outra forma de contemplar as crianças na política governamental. Foi no seu modo contraditório de ser e de pensar a infância e a humanidade que ele pôde conceber o PI como um espaço do brincar gratuito, "à toa", e outros modos de brincar nem sempre ao gosto da educação escolar, na sociedade capitalista. Ainda hoje, aqueles que pensam a educação infantil como uma modalidade de antecipar a escola de $1^{\circ}$ grau terão dificuldade de entender a importância do PI de Mário de Andrade.

A sua preocupação com o outro, com a construção da identidade cultural brasileira, através de uma linguagem poética, não-acadêmica, permite alcançar para a área da educação, novas dimensões de que ela urgentemente necessita.

Mário é macunaímico. E, assim como ele, o Brasil: uma identidade que não é uma; sua especificidade está na indefinição que, por sua vez, reúne muitas definições e muitas especificidades; possibilita aos opostos se encontrarem; "sem nenhum caráter" é a pluralidade de caracteres diversos. Pensando dessa forma, é que foi possível pensar a criança de uma maneira diferente das usuais: o fato de a criança não falar, ou não escrever, ou não saber fazer as coisas que os adultos fazem transforma-a em produtora de uma cultura infantil, justamente através "dessa(s)" especificidade(s). A ausência, a incoerência e a precariedade características da infância, em vez de serem "falta", incompletude, são exatamente a infância. Para encerrar, mais uma vez, vejamos como Mário de Andrade referiu-se à criança:

A criança é essencialmente um ser sensível à procura de expressão. Não possui ainda a inteligência abstraideira completamente formada. A inteligência dela não prevalece e muito menos não abumbra a totalidade da vida sensível. Por isso ela é muito mais expressivamente total que o adulto. Diante duma dor: chora - o que é muito mais expressivo do que abstrair: "estou sofrendo". A criança utiliza-se indiferentemente de todos os meios de expressão artística. Emprega a palavra, as batidas do ritmo, cantarola, desenha. Dirão que as tendências dela inda não se afirmaram. Sei. Mas é essa mesma vagueza de tendências que permite pra ela ser mais total. E aliás as tais "tendências" muitas vezes provêm da nossa inteligência exclusivamente. (Andrade 1929, p. 82) 


\section{Notas}

1. Quase $30 \%$ dos 1.624 freqüentadores dos três primeiros Pls: Parque Dom Pedro, Lapa e Ipiranga (Lowrie1937). Cabe informar que em 1937 o DC criou o Clube de Menores Operários para jovens trabalhadores de 12 a 21 anos, que funcionava nos PIs das 18 às 22 horas.

2. "O terreno era todo grande, e havia bancos para a gente sentar no meio das flores. Era lindo! O parque tinha poucas salas. Era só o lugar onde serviam - lanche e a salinha onde Dona Ida ensinava os trabalhos manuais" (Depoimento de ex-usuário do PI, Escola Municipal, 1985, p. 29).

3. Embora o PI no seu início tivesse apenas a instrutora para educar as crianças, com o advento das pesquisas sobre a precária condição de vida da classe operária paulistana realizadas pela Divisão de Documentação Histórica e Social da Prefeitura Municipal de São Paulo (PMSP), em 1936 é criada a função da educadora sanitária. Ao mesmo tempo que vemos a educação junto com o cuidado, vemos também a sua separação entre dois profissionais distintos, produto tanto da visão higienista da época, como do humanismo dos administradores, preocupados com as doenças infantis, a má alimentação das famílias usuárias etc. Ver em anexo as respectivas funções complementares definidas no Ato 1.146 de 1937 e o detalhamento da função da instrutora no "Regimento Interno dos Parques Infantis" que concretiza o mesmo Ato.

4. É o caso, por exemplo, da experiência dos Centros Polivalentes de Educação e Cultura (Cepec) do município de Piracicaba (SP) no final da década de 1970, começo de 1980 (Faria e Mello 1995), município que desde os anos 40 tinha PI em funcionamento.

5. Benjamin, em 1928, no seu texto sobre teatro proletário, demonstra a mesma preocupação de seu contemporâneo Mário de Andrade em relação à educação das crianças operárias e à não-interferência direta do adulto nos grupos infantis. Benjamin (1984) insiste na influência indireta do adulto antes da puberdade, quando, aí sim, se inicia a educação ideológica e o jovenzinho passará a ser instruído de modo proletário através de ensinamentos científicos (na técnica, na história de classe, na capacidade de discutir). Para crianças de 4 anos, o autor sugere o teatro infantil, como um espaço próprio para garantir a plenitude da infância, onde o jogo e a realidade se confundem e o papel do adulto é exclusivamente o de observar: cada ato ou gesto infantil torna-se um sinal, não do inconsciente, mas um sinal de um mundo em que a criança vive e comanda. No jogo cênico a sua infância realiza-se e durante a representação as crianças instruem e educam os educadores.

6. Mário de Andrade viajou muito pelo Brasil e trazia para a formação das instrutoras dos PIs material coletado nas suas pesquisas sobre o folclore nacional. É o caso por exemplo do material recolhido na sua viagem à Amazônia, que permitiu a 300 crianças do PI Dom Pedro II dramatizar "Seis lendas ama- 
zônicas", evento devidamente documentado com fotos e com o respectivo texto produzido pelo poeta (DC 1941).

7. "Nossos antepassados recomendavam a música como paidea, como educação e cultura, como algo que não é necessário nem útil, como ler e escrever, mas serve simplesmente para gastar o tempo livre (...) O gozo da música aproxima-se desse fim último (diagoguê) da ação, devido ao fato de não ser procurado em função de um bem futuro, mas em função de si mesma (...) portanto, fica claro que precisamos educar-nos para esta diagoguê e aprender certas coisas, mas não, note-se bem, em nome de trabalho, e sim em nome delas próprias" (Huizinga op.cit, pp. 180-181). De acordo com Huizinga, a música é a manifestação mais completa do prazer pelo prazer. Não foi à toa a arte que mais atraiu Mário de Andrade e conseqüentemente muito vivenciada no $\mathrm{PI}$.

8. Oneida Alvarenga, responsável pela Discoteca Pública Municipal, comentando o envolvimento de Mário no DC e seu desejo de dar ao povo o direito de uma existência elevada e dignificada pela atividade intelectual e o contato com as artes, afirmou que ele: "reativou nas praças e parques infantis as danças dramáticas e folclóricas, organizou corais nesses mesmos parques..."

9. Organizado pela saudosa pedagoga e jornalista Clea Nudelman, este número da Revista Escola Municipal foi totalmente dedicado aos 50 anos da rede municipal de educação infantil da PMSP, com um destaque especial aos primeiros parques infantis paulistanos.

10. Parte do texto resumido pelo articulista do Boletim del Instituto Internacional Americano de Proteción a la Infancia, ano VI, nº 1,1932, apud Miranda 1941, pp. 12-13.

11. Ver, em anexo, o "Regimento interno" (3.a) proibindo os jogos de futebol e de bola ao cesto para as crianças menores de 12 anos, assim como era proibido terminantemente o jogo de futebol aos domingos, sem exceção de idade (3.b). Fica a curiosidade: seria um nacionalismo exagerado de Mário de Andrade em relação a esportes de origem estrangeira?

12. "Nós recebíamos material nas reuniões, além de exemplos e sugestões. Por exemplo, roda cantada ele [o Maestro Braunwieser, conselheiro de educação musical] dava uma e a gente pesquisava para ampliar o repertório. Era preciso trabalhar com todas as turmas, com números diferentes de acordo com as faixas etárias, adequando o trabalho. E, nessas atividades, ele fazia muita questão que se desenvolvesse o folclore brasileiro porque era um ardoroso amante do Brasil. Dava-se muita música folclórica, cantigas de roda e se fazia muita questão das bandinhas rítmicas. Alguns instrumentos a gente recebia, outros a gente construía com latinhas de fermento, cabo de vassoura, tampinha, casca de coco. Nesta bandinha, a gente era orientada para incluir até os pequenininhos, porque era todo um trabalho de desenvolvimento rítmico. A gente ensinava a letra das canções, ritmava e as crianças iam falando. Também desenvolvíamos a percepção auditiva e a linguagem, dentro da Educação Musical. O maestro fazia questão que a gente não aceitasse que dissessem que 'en- 
sinávamos musiquinhas', por causa do trabalho que estava por trás" (depoimento da ex-professora Vitalina, Escola Municipal, op. cit, p. 22).

13. Por exemplo: "Vícios e defeitos na fala da criança operária - no seu aspecto médico, fonético e pedagógico" (Bueno dos Reis e Nicanor Miranda, Anais do I Congresso de Língua Nacional Cantanda), "Samba rural paulista" (Mário de Andrade, RAM, 1937), "Origem da população da cidade de SP e diferenciação das classes sociais" (Samuel Lowrie, RAM, nำ43, 1938), "A mobilidade da população paulista através de seu crescimento" (Gustavo de Godoy FiIho, RAM, no 17, 1935), "A alimentação das crianças" (RAM, nํ 33,1937), "Dextrismo e ambidextrismo" (RAM, no 35, 1937), "A questão da freqüência infantil aos cinemas" (Rui Cardoso, RAM, n 36,1937 ), "Padrão de vida das famílias dos operários da limpeza pública da municipalidade de S.P." (Lowrie, $\left.R A M, \mathrm{n}^{\circ} 51,1938\right)$, "Ensaio de um método de estudo da distribuição da nacionalidade dos pais dos alunos dos grupos escolares da cidade de SP" (RAM, no 25, 1936), "Ensaio de um método de investigação do nível social de SP pela distribuição da profissão dos pais dos alunos das escolas primárias públicas" (DC e Inst. de Educação da USP. RAM, no 23, 1936), "Inquérito sobre a alimentação popular em um bairro de SP - Pinheiros" (Paula Souza, Ulhoa Cintra e Egydio de Carvalho. RAM, no 17, 1935), "Nau Catarineta" (Mário de Andrade, publicada apenas em 1941, RAM, no 73), "Acidentes nos PIs de S. Paulo" (Bueno dos Reis,1941), "A pediculose nos PIs de S. Paulo" (coleta de dados realizada no PI D. Pedro II, 1938, Bueno dos Reis, 1941), "Peso, estatura e capacidade vital das crianças dos PIs de SP" (Bueno dos Reis, 1941) e "Assistência médica e educação da saúde em PIs" (início da coletada de dados em 1938), "Deficientes respiratórios nos PIs de SP" (Bueno dos Reis, 1941), "Influência portuguesa nas rodas no Brasil" (Mário de Andrade), "Ascendência das crianças registradas nos Parques Infantis de SP" (Lowrie, RAM, no 41, 1937), "Alguns casos de tuberculino-reação de Pirquet e Mantoux nos Pis" (DC,1939), "Técnica do jogo infantil organizado" (Miranda).

14. O livro publicado por Nicanor Miranda, 200 jogos infantis, nada mais é do que o levantamento das brincadeiras realizadas nos PIs, embora possamos (e devamos) criticar suas análises e classificações.

15. Essa é mais uma das idéias marioandradinas que se aproximam do pensamento de Vygotsky. Até Piaget, que também leu Luquet, nessa mesma época também não descobriu que a criança inverte algumas seqüências daquelas desenvolvidas pela humanidade, como a geometria?

16. Todos esses documentos encontram-se no IEB/USP. O curso completo de filosofia e história da arte, ainda inédito quando realizei minha pesquisa, está para ser publicado pela Hucitec. Os desenhos estão à espera de pesquisadores interessados em dar a palavra à infância! O Grêmio da FAU-USP editou boa parte do curso (Andrade 1966). A pasta V: 6 a ança, conservada pelo IEB (cujos manuscritos eu tive o privilégio de manusear), contém uma pastinha de papel intitulada "Estudos sobre o desenho infantil entre as crianças de São Paulo sob o ponto de vista da beleza". 
17. Entre elas: Agora eu quero cantar, Tempo da Camisolinha, Piá não sofre? Sofre, Rito do Irmão Pequeno, Reconhecimento de Nêmesis, Vestida de Preto, Cai, cai balão, e inclusive Macunaíma.

18. Enquanto Mário de Andrade estava voltado para o conhecimento dos problemas nacionais (com as idéias do modernismo, nas quais renovação/tradição convivem, e a pesquisa folclórica colaborando na construção da identidade brasileira, através da constatação do diferente, do outro, do homem comum, da criança, do operário, do homem do campo, do nordeste etc.), os folcloristas em geral falavam em nome do outro, distinguindo o que tem valor do que não tem valor e, assim, discriminando ora um positivo, ora outro negativo (Mello e Souza 1989), escamoteando a diferença para encontrar a identidade nacional (Ortiz, apud Mello e Souza op. cit.).

19. Estou entendendo trabalho aqui, como sua manifestação nas sociedades contemporâneas através da exploração e da alienação, portanto, as crianças não devem trabalhar. (Diferente, portanto, do binômio trabalho-jogo, como atividades humanas.) Além do que, Mário de Andrade disse: "O exercício da preguiça que eu cantei em Macunaíma é uma das minhas maiores preocupações". Para ele, a arte nasce do ócio, é filha da preguiça, é deformadora da natureza, e, com 25 anos, escreveu a Divina Preguiça (ainda com fortes marcas do cristianismo). Segundo ele, a arte nasceu "dum bocejo sublime, assim como o sentimento do belo deve ter surgido duma contemplação ociosa da natureza". Não parece desprovido de sentido o comentário feito por uma ex-professora do PI: "Havia o momento do repouso e, quando o dia estava bonito, iam ficar deitadinhos na grama, à sombra. O repouso era o que mais eles gostavam." (Escola Municipal op. cit.)

\title{
The contribution of Mário de Andrade's 'parques infantis' to the construction of a pedagogy of early childhood education
}

\begin{abstract}
The "Parques infantis" of the Department of Culture of the city of São Paulo in their first three years (1935-1938) during Mário de Andrade term as director were part of a governmental non-schooling educational project for young children from workingclass families, through which their right to childhood was assured. The research on our folklore performed by the poet-educator ("300-350") and the brazilian ethnical diversity made up the fundamentals of this educational experience in which children relived popular traditions, had the chance of being children through art and traditional child play, of experiencing the specifics of that age. The architectural plan and the rules and regulations of the "parques infantis" are pointed out here showing, among other characteristics, elements for the construction of a pedagogy of early childhood education.
\end{abstract}




\section{Documentos Anexos}

\section{Documento 1}

\section{Departamento de Cultura - Divisão de Educação e Recreio Regimento Interno dos Parques Infantis}

C- Compete aos instrutores:

\section{$\left.1^{\circ}\right)$ Em relação ao serviço geral dos Parques:}

a) zelar pela conservação dos parques, seus abrigos, pergolas, telheiros e aparelhos;

b) providenciar o preparo dos aparelhos que por falta de resistência ou qualquer defeito, não oferecem segurança;

c) providenciar para que os tanques de brincar sejam constantemente alimentados com água corrente e renovada a areia dos taboleiros;

d) colaborar com o chefe da Seção na execução de tudo quanto se refira aos fins sociais da repartição, propondo-Ihe medidas e iniciativas oriundas da observação e da experiência, tendentes a um constante aperfeiçoamento da Seção;

e) atrair as crianças para os brinquedos próprios à sua idade, desviando-as de todos aqueles que sejam contra-indicados;

f) orientar as atividades recreativas da criança, velando por ela, sem Ihe perturbar ou ameaçar a liberdade e a espontaneidade no brinquedo;

g) auxiliar na distribuição do leite, merendas, etc;

h) ensinar a prática de jogos infantis, participando das atividades lúdicas e recreativas;

i) propagar a prática dos brinquedos e jogos nacionais, cuja tradição as crianças já perderam ou tendem dia-a-dia a perder;

j) promover a prática de jogos, que pela experiência universal, forem dígnos de incorporação do patrimônio dos inspirados nas tradições nacionais; 
k) aproveitar as oportunidades proporcionadas pelo interesse das crianças para Ihes ministrar educação física.

\section{$\left.2^{\circ}\right)$ Em relação às crianças, compete aos instrutores:}

a) fazer um livro apropriado, a matrícula das crianças, encaminhando-as em seguida ao médico, afim de serem preenchidas as diferentes fichas;

b) tornar obrigatório o uso de uniforme no Parque;

c) tornar obrigatório, nos tanques de vadear e nas piscinas, o uso de "maillot";

d) proibir que o banho de piscina vá além de 30 minutos. O banho pode ser misto. Caso haja meninas que não desejem participar do banho misto, será permitido marcar para elas um período igual em hora diferente;

e) organizar o horário de ginástica e do banho, de maneira a deixar o tempo necessário à digestão da merenda;

f) verificar cuidadosamente se as crianças que participam das festas e torneios estão autorizadas pelo médico do serviço;

g) vedar expressamente às crianças que figurarem na relação afixada pelo médico do serviço, a participação em qualquer atividade afim de tornar-se uma realidade o afastamento de crianças doentes ou suspeitas como tal;

h) determinar aos guardas dos portões que usem de toda a energia para afastar da entrada dos Parques os vendedores ambulantes de doces ou gulodices prejudiciais à higiene e saúde das crianças;

i) fiscalizar a colaboração destinada aos jornaizinhos de maneira que os originais sejam compostos sob as vistas do instrutor;

j) verificar que todo e qualquer trabalho (desenho, pintura, etc) das crianças traga sempre o nome e a idade do autor;

k) entregar a esta chefia afim de constituir parte do arquivo do Departamento da Cultura, os desenhos feitos pelas crianças;

I) tornar obrigatória a lavagem das mãos antes do copo de leite, cuja distribuição deve ser feita de acordo com o horário das refeições das crianças;

m) impedir que a criança brinque debaixo de chuva ou sol muito forte; 
n) impedir que os guardas intervenham no serviço educacional das crianças a não ser por ordem direta de instrutores, em caso de acidentes ou em caso de conflitos e brigas entre elas. (É expressamente proibido aos guardas o uso de varinhas ou bastões).

\section{$\left.3^{\circ}\right)$ Em relação aos jogos, compete aos instrutores:}

a) proibir os jogos de futebol e bola ao cesto, às crianças menores de 12 anos. Para os maiores de 12 anos, deve ser feita a redução do campo de acordo com a idade dos jogadores e determinado o tempo máximo de duração do jogo. (25 minutos e nunca mais de 3 vezes por semana);

b) proibir terminantemente o jogo de futebol aos domingos, sem exceção de idade, ficando os vigilantes responsabilizados pela prática desses jogos nesses dias;

c) proibir expressamente a realização de qualquer jogo entre os Parques sem prévia anuência e aprovação da chefia;

d) organizar os jogos e demais atividades de campo de forma a ser utilizado somente um gramado durante um período de noventa dias, evitando realizações de jogos no gramado impedido, afim de conseguirse novo viço;

e) determinar que a prática de futebol, assim como a de natação, só seja permitida às crianças matriculadas nos cursos de ginástica;

f) impedir, sob qualquer pretexto, entrada ou saída de materiais de jogos, como sendo bolas, petecas, cordas, etc. e bicicletas, carrinhos, etc. a não ser aos domingos e feriados;

g) estimular na criança o espírito poliesportivo, evitando assim atração exagerada por um determinado jogo.

h) proibir que as crianças pratiquem jogos de bola, peteca ou outros, nos galpões ou onde possam danificar os ventiladores, janelas, vidros ou paredes;

i) apresentar com antecedência mínima de 15 dias os programas de jogos, torneios ou festas que se realizam internamente nos Parques;

j) exercitar continuamente as crianças nas provas de arremessso de bola, salto e altura, corridas de 50 a 75 metros, afim de assegurar um treino perfeito para a Olimpíada Infantil. 


\section{$\left.4^{\circ}\right)$ Em relação aos serviços internos e externos dos Parques e seus funcionários subalternos, compete às instrutoras:}

a) comparecer às reuniões na chefia, festivais e outras realizações fora do Parque, quando para isso especialmente convocadas; o não comparecimento acarreta a aplicação do que dispõe o Ato 1.146 , art. 327 , parágrafo $2^{\circ}$. As reuniões realizam-se quinzenalmente no $2^{\circ}$ e no último sábado de cada mês, às 10 horas em ponto, devendo as instrutoras assinar o nome em livro para isso designado, a cargo do funcionário Edmundo Caldera. As reuniões obedecem ao seguinte plano: $2^{\circ}$ sábado - Expediente, sugestões e informações diversas - Leitura dos relatórios; $4^{\circ}$ sábado: Reunião pedagógica.

b) organizar todas as atividades fora do recinto do Parque, salvo em casos especiais, aos domingos e feriados ou em período diferente ao do respectivo trabalho;

c) zelar pelos próprios municipais bem como por todas as instalações, acessórios e utensílios dos Parques, os quais devem merecer-lhes o maior cuidado. Qualquer perda, extravio, quebra ou estrago deve ser imediatamente comunicado à chefia;

d) comunicar à chefia a falta de areia fina para os "stands" e chãos e balanças, carrocéis, gangorras, passos-gigantes, etc;

e) providenciar para que seja observado o maior asseio possível no recinto dos parques, evitando que as crianças atirem ao chão papéis ou outros objetos;

f) ordenar o esvaziamento dos tanques de vadear, aos domingos;

g) proibir que sejam tiradas fitas ou fotografias nos Parques, por fotógrafos profissionais, sem autorização da chefia;

h) não dar atribuições a servidores municipais que não pertencem à Divisão e nem estejam diretamente subordinados à chefia;

i) reservar diariamente meia hora do período de trabalho para colaborar com o médico assistente do Parque, na organização das fichas e registro geral das crianças;

j) não dar atestados sobre o comportamento de vigilantes e zeladores dos Parques, ainda mesmo que por eles solicitados; 
k) fornecer aos vigilantes do portão, a relação das crianças afastadas preventivamente do Parque;

I) comunicar à chefia qualquer modificação que interesse ao prontuário dos vigilantes e zeladores, tais como mudança do estado civil, de residência, etc;

m) providenciar para que não seja permitida a entrada de adultos nos Parques, a não ser com expressa autorização superior;

n) comparecer às reuniões mensais internas que se realizam nos Parques sob a presidência do médico;

o) encaminhar à chefia da Seção, devidamente informados, os pedidos de abono, justificação de faltas ou férias dos vigilantes e zeladores;

p) apresentar-se uniformizada durante o tempo de trabalho: blusa branca e calção azul para as aulas de ginástica e avental branco com distintivo para as outras atividades;

q) apresentar mensalmente (nos moldes de modelo) o relatório dos serviços realizados nos Parques. Os documentos e dados constantes do esquema são obrigatórios. Fica dispensado todo e qualquer gráfico referente a estatística. A chefia receberá, no entanto, com prazer, quaisquer elementos desse gênero que as instrutoras queiram elaborar ou apresentar;

r) fiscalizar o trabalho dos vigilantes e zeladores.

$\left.5^{\circ}\right)$ Os cheques serão distribuídos na chefia, no $2^{\circ}$ dia útil de cada mês, contra a entrega do relatório mensal.

Aplicam-se aos casos omissos neste regimento as disposições do Ato 1.146 de $04 / 07 / 1937$.

\section{Documento 2}

\section{Ato № 1.146 de 04 de Julho de 1936}

Consolida e modifica disposições referentes aos serviços, repartições e funcionários da prefeitura e dá outras providências.

"Divisão de Educação e Recreio" 


\section{Art. $206^{\circ}$ - Aos educadores sanitários compete:}

a) auxiliar o médico e o dentista nos seus serviços especializados;

b) zelar pela saúde das crianças, investigar as condições do meio social de que provierem e encaminhar as suspeitas de moléstias, ou necessidades de tratamento ao Departamento de Higiene;

c) formar a consciência sanitária das crianças incutindo-Ihes hábitos higiênicos;

d) estabelecer acordo com o médico, as medidas convenientes para a melhoria do estado de nutrição das crianças;

e) estudar as crianças sob o ponto de vista biológico, psíquico e social e auxiliar o médico na organização de fichas clínicas;

f) estabelecer as fichas biológicas, organizar e manter o respectivo arquivo;

g) praticar serviços de enfermaria, vacinações e revacinações, injeções intra-musculares, análises e pequenas cirurgias de emergência;

h) organizar e praticar o serviço de visitas domiciliares aos responsáveis pelas crianças, conhecimentos de higiene, profilaxia e cozinha dietética;

i) fiscalizar e dirigir o trabalho dos zeladores;

j) organizar, regulamentar e fiscalizar o serviço de alimentação nos Parques das crianças desnutridas;

\section{Art. $207^{\circ}$ - Aos instrutores compete:}

a) zelar pela conservação dos parques, seus abrigos, pergolas, telhados e aparelhos;

b) providenciar o reparo de aparelhos que, por falta de resistência ou outro qualquer defeito, não ofereçam segurança;

c) providenciar para que os tanques de brincar sejam constantemente alimentados com água corrente e renovada a areia dos taboleiros;

d) colaborar com o chefe da seção na execução de tudo quanto se refira aos fins sociais da repartição, propondo-Ihe medidas e iniciativas 
oriundas da observação e da experiência, tendentes a um constante aperfeiçoamento da seção;

e) atrair as crianças para os brinquedos próprios à sua idade, desviando-as de todos aqueles que sejam contra-indicados;

f) orientar as atividades recreativas da criança, velando por ela, sem Ihe perturbar ou ameaçar a liberdade e a espontaneidade no brinquedo;

g) ensinar a prática de jogos infantis, participando das atividades lúdicas e recreativas;

h) propagar a prática de brinquedos e jogos nacionais cuja tradição as crianças já perderam ou tendem dia-a-dia a perder;

i) promover a prática de jogos que, pela experiência universal foram dignos de incorporação ao patrimônio dos inspirados nas tradições nacionais;

j) aproveitar as oportunidades proporcionadas pelo interesse das crianças para lhes ministrar educação física;

k) fiscalizar e dirigir os trabalhos dos vigilantes.

\section{Documento 3}

Planta das dependências e Planta Geral do Parque Infantil de Santo Amaro (1938)

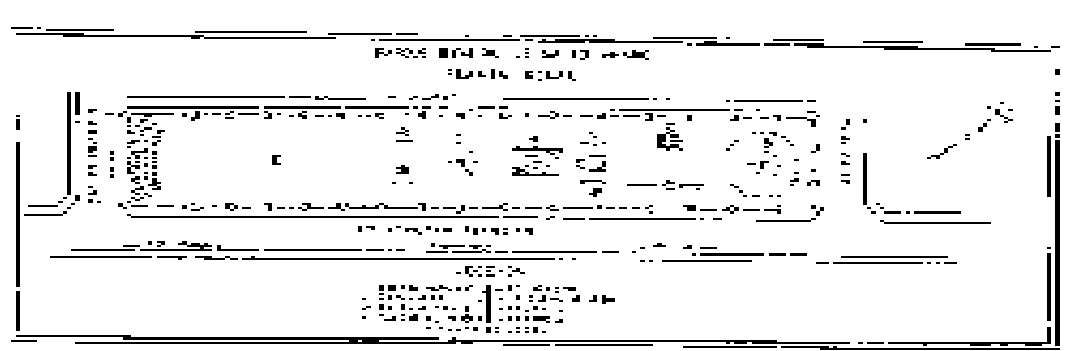

Fonte: Miranda, 1938, pp. 27-28 


\section{Documento 4}

Planta das dependências e Planta Geral do Parque Infantil de Santo Amaro (1938)

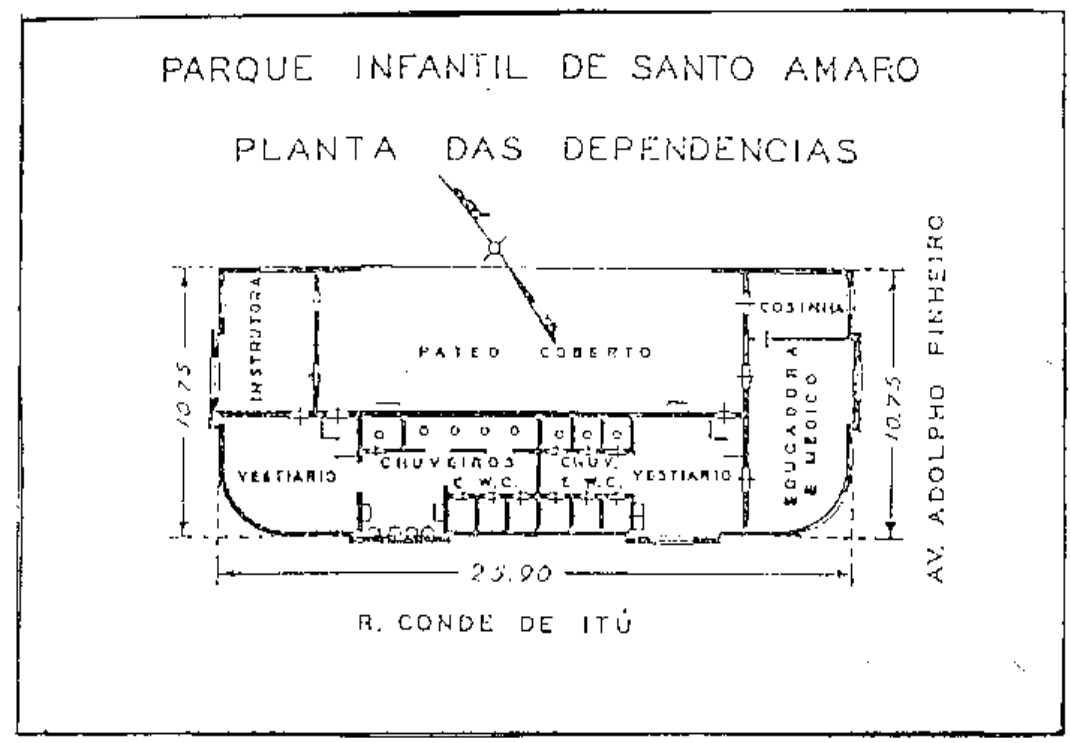

Fonte: Miranda 1938, pp. 27-28

\section{Bibliografia}

ANDRADE, Mário. "Folclore". In: BORBA DE MORAES, Rubens. Manual bibliográfico de estudos brasileiros. Rio de Janeiro: Souza, 1949. . "5a parte - A criança". In: Centro de Estudos Brasileiros, G FAU. Depoimentos 2. 1966, pp. 67-76.

. "Do desenho". In: Aspectos das artes plásticas no Brasil. São Paulo, Martins, 1975, pp. 71-77. 
. "Sonoras crianças". In: Música, doce música. 2ª ed. São Paulo: Martins, 1976, pp. 303-308.

. "Criança-prodígio (1929)". In: Taxi e crônicas no Diário Nacional. São Paulo: Duas Cidades,19x6

BENJAMIN, Walter. Reflexões: A criança, o brinquedo, a educação. São Paulo: Summus, 1984.

CAILLOIS, Roger. I giochi e gli uomini. Milão: Bompiani,1982.

DEPARTAMENTO DE CULTURA. Divisão de ensino e recreio. Legislação dos parques infantis, 1936.

. Divisão de ensino e recreio. Regimento interno dos parques infantis. s/d. (relacionado ao ato 1.146 de 4/7/1937).

. Divisão de Educação e Recreio. Seis lendas amazônicas. 1941.

DUARTE, Paulo. Mário de Andrade por ele mesmo. São Paulo: Edarte, 1971.

ESCOLA MUNICIPAL. 50 anos de pré-escola municipal. v.18, no 13, 1985.

FARIA, Ana Lúcia G. "Direito à Infância: Mário de Andrade e os parques infantis para as crianças de família operária na cidade de São Paulo (1935-1938)". Tese de doutoramento. São Paulo: Feusp,1994.

. "As origens da rede pública municipal de educação infantil na cidade de São Paulo". Proposições, vol. 6, № 2 (17), 1995, pp. 34-45.

FARIA, Ana Lúcia G e MELLO, Suely A. "Educação e política no Brasil: Relato de uma Experiência". Cadernos da FFC-Unes. Marília, vol. 4, № 2, 1995, pp.133-146.

FINAZZI-AGRÒ, Ettore. "La parola in gioco: La reivenzione della memoria in 'Macunaíma'”. Rassegna Iberistica. Veneza, № 33, 1988, pp. 13-23.

HUIZINGA, Johan. Homo Ludens. São Paulo: Perspectiva, 1971.

KUHLMANN JÚNIOR, Moysés. "Instituições pré-escolares assistencialistas no Brasil (1899-1922)". Cadernos de Pesquisa. São Paulo, no 78, 1991, pp. 17-26.

LOWRIE, Samuel. "Ascendência das crianças registradas nos parques infantis de São Paulo". RAM - Revista do Arquivo Municipal, oo 41, 1937, pp. 21-33.

MAC-IEB. "Mário de Andrade e a criança". Catálogo da Exposição Comemorativa dos 25 anos do MAC e do IEB. 1988. 
MARINHO, Inezil. Educação física, recreação e jogos. São Paulo: Cia Brasil, 1971.

MELLO E SOUZA, Marina. "Folclore e cultura brasileira: Os missionários da nacionalidade". XIII Anpocs, 1989.

MIRANDA, Nicanor. O significado de um parque infantil em Santo Amaro. Departamento de Cultura. Divisão de Ensino e Recreio. 1938.

Origem e propagação dos parques infantis e parques de jogos. São Paulo: Departamento de Cultura da PMSP, 1941. 